\title{
Effects of dietary DHA and $\alpha$-tocopherol on bone development, early mineralisation and oxidative stress in Sparus aurata (Linnaeus, 1758) larvae
}

\author{
M. S. Izquierdo ${ }^{1 *}$, M. Scolamacchia ${ }^{1}$, M. Betancor ${ }^{1}$, J. Roo $^{1}$, M. J. Caballero ${ }^{1}$, G. $_{\text {Terova }}{ }^{2}$ \\ and P. E. Witten ${ }^{3}$ \\ ${ }^{1}$ Grupo de Investigación en Acuicultura, Universidad de Las Palmas de Gran Canaria $\xi$ \\ Instituto Canario de Ciencias Marinas, P.O. Box 56, 35200 Telde, Canary Islands, Spain \\ ${ }^{2}$ Department of Biotechnology and Molecular Sciences, University of Insubria, Varese, Italy \\ ${ }^{3}$ Skretting Aquaculture Research Centre, P.O. Box 48, 4001, Stavanger, Norway
}

(Submitted 6 January 2012 - Final revision received 26 July 2012 - Accepted 1 August 2012 - First published online 10 October 2012)

\section{Abstract}

DHA deficiency has been related to skeletal malformations in fish, but high DHA levels have produced controversial results that could relate to the oxidative status of fish tissues in the different reports. In the present study, gilthead seabream (Sparus aurata) larvae were fed deficient, adequate or high DHA levels, or high DHA levels supplemented with the antioxidant $\alpha$-tocopherol. Larvae fed deficient DHA levels tended to be smaller, and showed the highest incidence of urinary bladder calculi, lordosis and kyphosis and the lowest number of mineralised vertebrae for any given size class. Elevation of dietary DHA increased larval growth and significantly enhanced the expression of the insulin-like growth factor $1(I G F-1)$ gene. However, a DHA level increase up to $5 \%$ raised the degree of lipid oxidation in larval tissues and deformities in cranial endochondral bones and in axial skeletal haemal and neural arches. The increase in dietary $\alpha$-tocopherol supplementation in high-DHA feeds reduced again the occurrence of skeletal deformities. Moreover, the expression of genes coding for specific antioxidants such as catalase, superoxide dismutase or glutathione peroxidase, which neutralised reactive oxygen substances formed by increased dietary DHA, was significantly decreased in larvae fed high $\alpha$-tocopherol levels. These results denoted the importance of DHA for early bone formation and mineralisation. Low dietary DHA levels delay early mineralisation and increase the risk of cranial and axial skeletal deformities. Excessive DHA levels, without an adequate balance of antioxidant nutrients, increase the production of free radicals damaging cartilaginous structures before bone formation.

Key words: Essential fatty acids: Cranial abnormalities: Vertebral column anomalies: Bone mineralisation

Many genetic and epigenetic factors have been linked to skeletal abnormalities in cultured teleost fish ${ }^{(1)}$. Among the nutritional factors, several vitamins and minerals have recently been recognised to influence the occurrence of skeletal malformations ${ }^{(2-4)}$. Other nutrients such as dietary lipids have also been related to skeletal anomalies ${ }^{(5-8)}$. For instance, dietary phospholipids reduce the incidence of skeletal abnormalities in ayu larvae (Plecoglossus altivelis) ${ }^{(9)}$ and in European sea bass (Dicentrarchus labrax) ${ }^{(5)}$. In particular, DHA has been related to skeletal malformations that occur in early larval stages of marine fish ${ }^{(10)}$. Increased DHA levels markedly reduced the occurrence of malformed fish $(20 \cdot 1 \%$ in larvae fed DHA-rich rotifers $v .51 \%$ in larvae fed control rotifers) in red porgy (Pagrus pagrus) ${ }^{(6)}$ and milkfish (Chanos chanos) ${ }^{(11)}$. However, elevation of both DHA and EPA levels over $2 \%$ in the neutral lipid fraction of compound diets led to skeletal abnormalities in European sea bass ${ }^{(12)}$. Betancor et al. ${ }^{(13)}$ also described the deleterious effects of excessive DHA contents in microdiets for sea bass. A high dietary DHA content increases peroxidation risks. Consequently, the deleterious effects caused by high DHA contents could be related to the proliferation of free radicals, derived from this fatty acid, and to the formation of toxic oxidised compounds that subsequently negatively affect bone development ${ }^{(10)}$.

To control the formation of these reactive oxygen species, the fish antioxidant system includes a series of compounds that together neutralise reactive oxygen species. Components of the antioxidant system are vitamins $\mathrm{C}$ and $\mathrm{E}$ and several enzymes such as superoxide dismutase (SOD), catalase (CAT) and glutathione peroxidases $(\mathrm{GPX})^{(14)}$. Thus, reactive

Abbreviations: CAT, catalase; DH, DHA high; DHE, DHA high $+\alpha$-tocopherol; DL, DHA low; DM, DHA medium; dph, days post-hatching; dw, dry weight; GPX, glutathione peroxidase; IGF-1, insulin-like growth factor 1; SOD, superoxide dismutase.

*Corresponding author: Professor M. S. Izquierdo, fax +34 928132908, email mizquierdo@dbio.ulpgc.es; www.grupoinvestigacionacuicultura.org 
oxygen species, such as $\mathrm{O}_{2}^{--}$, are converted to $\mathrm{H}_{2} \mathrm{O}_{2}$ by SOD, and then to $\mathrm{O}_{2}$ and water by several enzymes including CAT or $\mathrm{GPX}^{(15)}$. Differential expression of genes encoding these enzymes is considered as an effective method of denoting oxidative stress caused by an imbalance of oxidant/antioxidant compounds $^{(16)}$, following excessive dietary DHA. Other genes potentially affected by DHA and related to bone-forming tissues are insulin-like growth factors $(I G F)$. Dietary PUFA may up-regulate or down-regulate the expression of such genes in fish tissues by modulating PG production as well as the expression of IGF-binding proteins. IGF-1, in particular, functions as both systemic and local growth factors for different tissues by stimulating cell proliferation and differentiation $^{(17)}$. In mammalian bone, locally produced IGF-1 stimulates new bone cell formation and matrix production ${ }^{(18)}$.

Since many malformations originate early during fish development, a better understanding of the processes of bone formation would allow a better control of the occurrence of bone anomalies ${ }^{(19)}$. Most bony elements of the endoskeleton have a cartilaginous precursor that is replaced by bone in the frame of endochondral bone formation ${ }^{(20)}$. Typical, mammalian-like, endochondral bone formation is often lacking in teleost fish. Especially, in fish larvae, bone develops around cartilaginous elements (perichondral bone). The cartilage inside the bone collar can remain intact or can be replaced by adipose tissue. Indeed, rather than simply bone and cartilage, fish skeletal tissue is often best described as a continuous spectrum ranging from the connective tissue to the cartilage and to the bone ${ }^{(20)}$. Bone is a specialised vascularised connective tissue consisting of cells and a mineralised extracellular matrix. Before being mineralised, the extracellular matrix is composed mainly of collagen type I called osteoid that subsequently becomes mineralised through the osteoblastmediated deposition of hydroxyapatite ${ }^{(20)}$. Cartilage is an avascular skeletal tissue composed of chondrocytes that are embedded in an extracellular matrix primarily composed of collagen type II and proteoglycans. Chondroid bone is an intermediate tissue that is found, for example, in the mandibular and maxillary tissue of teleost fish and has intermediate characteristics of both bone and cartilage, containing both collagen types I and II, and may be mineralised. In teleosts, such as gilthead seabream (Sparus aurata), the formation of the vertebral body centrum is initiated by direct mineralisation of the notochordal sheath. In a second step, intramembranous bone is deposited around the mineralised notochord sheath. Different from most basal bonefish and tetrapods, teleost vertebral body development does not pass through a cartilaginous stage ${ }^{(21,22)}$.

In order to better understand the dose-related effect of dietary DHA on early bone formation and on the development of skeletal anomalies, in the present study, gilthead seabream larvae were fed four different types of rotifers containing either deficient, adequate or excessive levels of this dietary fatty acid. A fourth type of rotifer contained the high DHA level and increased supplementation of $\alpha$-tocopherol to determine whether the negative effects of excess DHA can be prevented by an increasing level of a nutritional antioxidant.

\section{Experimental methods}

Eggs from a spontaneous spawning of a genetically characterised seabream broodstock of the Grupo de Investigación en Acuicultura (Canary Islands, Spain) were seeded at a concentration of $120 \mathrm{eggs} / \mathrm{l}$ in sixteen 170-litre cylindrical conical tanks. The tanks were provided with fluorescent light at $12 \mathrm{~h}$ dark $-12 \mathrm{~h}$ light and an air flow of $170 \mathrm{ml} / \mathrm{min}$. Temperature, dissolved $\mathrm{O}_{2}$ and $\mathrm{pH}$ recorded along the study were $20.66 \pm 0.65^{\circ} \mathrm{C}, 5.87 \pm 0.31$ parts per million and $8.26 \pm 0.08$ respectively. Determination of egg quality ${ }^{(23)}$ showed $98 \%$ viability in terms of morphologically normal eggs, $80.5 \%$ hatching rate and $89.06 \%$ survival of larvae $3 \mathrm{~d}$ after hatching (days post-hatching; dph).

The four enrichment treatments were prepared containing three different levels of DHA and two different levels of vitamin E (Table 1). A low DHA enrichment (DHA low, DL) was prepared with DHA Protein Selco ${ }^{\circledR}$ (Inve) where fatty

Table 1. Ingredients and analysed composition of the enrichment products used to feed rotifers to attain low (DL), medium (DM) or high (DH) DHA contents and high DHA contents with an extra supplement of $\alpha$-tocopherol (DHE)

(Mean values and standard deviations, $n 3$ )

\begin{tabular}{|c|c|c|c|c|c|c|c|c|}
\hline \multirow[b]{2}{*}{ Ingredients } & \multicolumn{2}{|c|}{$\mathrm{DL}$} & \multicolumn{2}{|c|}{ DM } & \multicolumn{2}{|c|}{$\mathrm{DH}$} & \multicolumn{2}{|c|}{ DHE } \\
\hline & Mean & SD & Mean & SD & Mean & SD & Mean & SD \\
\hline DHA Protein Selco ${ }^{\circledR}$ & \multicolumn{2}{|c|}{-} & \multicolumn{2}{|c|}{100} & \multicolumn{2}{|c|}{90} & \multicolumn{2}{|c|}{90} \\
\hline Defatted DHA Protein Selco ${ }^{\circledR}$ & \multicolumn{2}{|c|}{90} & \multicolumn{2}{|c|}{-} & \multicolumn{2}{|c|}{-} & \multicolumn{2}{|c|}{ - } \\
\hline Lipid source* & \multicolumn{2}{|c|}{10} & \multicolumn{2}{|c|}{ - } & \multicolumn{2}{|c|}{ - } & \multicolumn{2}{|c|}{-} \\
\hline MorDHAt & \multirow{2}{*}{\multicolumn{2}{|c|}{6000}} & \multirow{2}{*}{\multicolumn{2}{|c|}{$\begin{array}{c}- \\
6000\end{array}$}} & \multirow{2}{*}{\multicolumn{2}{|c|}{$\begin{array}{c}10 \\
6000\end{array}$}} & \multirow{2}{*}{\multicolumn{2}{|c|}{$\begin{array}{c}10 \\
10000\end{array}$}} \\
\hline$\alpha$-Tocopherol $(\mathrm{mg} / \mathrm{kg}) \ddagger$ & & & & & & & & \\
\hline \multicolumn{9}{|l|}{ Analysed nutrients } \\
\hline Lipids (\% dw) & $10 \cdot 93^{a}$ & 0.11 & $21 \cdot 36^{b}$ & 0.17 & $31 \cdot 11^{\mathrm{c}}$ & 0.23 & $31 \cdot 71^{\mathrm{c}}$ & 0.35 \\
\hline Ash $(\% d w)$ & 8.29 & 0.04 & $8 \cdot 25$ & 0.04 & $6 \cdot 42$ & 0.03 & $6 \cdot 40$ & 0.04 \\
\hline Protein $(\% d w)$ & 34.23 & 3.21 & 30.66 & 2.75 & $25 \cdot 62$ & 5.06 & 24.28 & 4.84 \\
\hline $\mathrm{DHA}(\% \mathrm{dw})$ & $0 \cdot 17^{\mathrm{a}}$ & 0.04 & $3 \cdot 20^{\mathrm{b}}$ & 0.15 & $13 \cdot 15^{\mathrm{c}}$ & 0.30 & $13 \cdot 84^{c}$ & 0.55 \\
\hline$\alpha$-Tocopherol (mg/kg) & $6393^{\mathrm{a}}$ & 134 & $6325^{\mathrm{a}}$ & 122 & $6149^{\mathrm{a}}$ & 161 & $11758^{\mathrm{b}}$ & 378 \\
\hline
\end{tabular}

dw, Dry weight.

${ }_{\mathrm{a}, \mathrm{b}, \mathrm{c}}$ Mean values with unlike superscript letters were significantly different $(P<0.05)$.

* Lipid source: EPA50 and arachidonic acid (CRODA) and oleic acid (Sigma-Aldrich).

† MorDHA omega-3 I.Q. (Minami Nutrition).

$\ddagger D L-\alpha$-Tocopherol acetate (Sigma-Aldrich). 
acids had been extracted by washing three times with chloroform (3:1, v/v, chloroform:enrichment) and substituted by a mixture of lipids with a similar fatty acid composition except for the low DHA content (EPA50 and arachidonic acid; CRODA and oleic acid; Sigma-Aldrich) and included $\alpha$-tocopherol (DL- $\alpha$-tocopherol acetate; Sigma-Aldrich) to reach a concentration of $6000 \mathrm{mg} / \mathrm{kg}$. A second enrichment (DHA medium, DM) contained the original DHA Protein Selco ${ }^{\circledR}$ plus $\alpha$-tocopherol to reach a concentration of $6000 \mathrm{mg} / \mathrm{kg}$. The third enrichment (DHA high, DH) contained DHA Protein Selco ${ }^{\circledR}$, a DHA-rich oil (MorDHA omega-3 I.Q.; Minami Nutrition) and $\alpha$-tocopherol to reach a concentration of $6000 \mathrm{mg} / \mathrm{kg}$. Finally, the fourth enrichment (DHA high $+\alpha$-tocopherol, DHE) was equal to the previous one, but increasing the $\alpha$-tocopherol content up to $10000 \mathrm{mg} / \mathrm{kg}$. These enrichments were kept at $+4^{\circ} \mathrm{C}$ along the trial. Rotifers were enriched for at least $8 \mathrm{~h}$ to allow the incorporation of DHA from either ethyl ester (DH and DHE) or TAG forms (DL and DM) into the TAG and phospholipid fractions of rotifers, in agreement with previous studies $^{(6)}$. After enrichment, rotifers contained $0 \cdot 25,2 \cdot 39,5 \cdot 24$ and $5 \cdot 27 \%$ DHA dry weight (dw) for the DL, DM, DH and DHE enrichments, respectively (Table 2 ).

The feeding regimen resemble that of commercial hatcheries and was as follows: from 3 to $25 \mathrm{dph}$, larvae were fed rotifers enriched with one of the four different enrichment mediums described: DL, DM, DH or DHE at a concentration of 10 rotifers $/ \mathrm{ml}$; from 15 to $34 \mathrm{dph}$, larvae were also fed enriched (DHA Easy Selco ${ }^{\circledR}$; Inve) Artemia sp. (0.25-0.5 nauplii/ml) and from 24 to $34 \mathrm{dph}$ with a weaning dry feed (Gemma Micro; Skretting). Therefore, feeding regimens only differed in the enrichment medium of rotifers between 3 and $25 \mathrm{dph}$, although larvae were reared until bone mineralisation at $34 \mathrm{dph}$ for skeleton and mineralisation studies.
For each treatment, four replicates were tested until $15 \mathrm{dph}$, when, in order to determine the effect of rotifer feeding on fish biochemical composition before feeding with Artemia sp., larvae from one tank per treatment were collected for biochemical analysis. After $15 \mathrm{dph}$, three replicates were kept for each treatment until the end of the trial at $34 \mathrm{dph}$.

The time of sampling was as follows: rotifers from each feeding treatment were sampled every $3 \mathrm{~d}$ for biochemical analysis; to determine the effect of rotifer feeding on larval growth, larvae were sampled at 3 (first feeding), 15 (before Artemia sp. feeding), 20 (end of maximum rotifer intake by the larvae) and $34 \mathrm{dph}$ (end of the trial), standard length of thirty larvae per tank was measured by a profile projector (PJ-A3000; Mitutoyo) and dry body weight of thirty larvae per tank was obtained by drying them at $105^{\circ} \mathrm{C}$ until constant weight; to determine feed ingestion, the abdominal cavity of five larvae per tank was photographed every $3 \mathrm{~d}$ until the end of the experiment; to determine swim bladder inflation, twenty larvae per tank were sampled at 7 and $12 \mathrm{dph}$ (period of first inflation of seabream swim bladder); to determine the effect of rotifer feeding on larval biochemical composition and thiobarbituric acid reactivity, all the larvae from one tank per treatment were collected at $15 \mathrm{dph}$ (before Artemia sp. feeding), and analyses performed in two subsamples of that population; for gene expression studies at this age ( $15 \mathrm{dph})$, fifty larvae per tank were sampled; to determine the larval welfare status, fifteen larvae per tank were sampled at $20 \mathrm{dph}$ (end of maximum rotifer intake by the larvae) and subjected to an acute stress of handling them out of the water for $60 \mathrm{~s}$ and returning them to a bucket with aerated fresh water to determine larval survival $24 \mathrm{~h}$ later ${ }^{(24)}$; to determine the occurrence of skeleton anomalies and mineralisation, 150 larvae per treatment were sampled

Table 2. Proximate (\% dry weight (dw)) and fatty acid (\% total fatty acid) composition of total lipids of rotifers fed enrichments with low (DL), medium (DM) or high (DH) DHA contents and high DHA contents with an extra supplement of $\alpha$-tocopherol (DHE)*

(Mean values and standard deviations, $n 8$ )

\begin{tabular}{|c|c|c|c|c|c|c|c|c|}
\hline \multirow[b]{2}{*}{ Fatty acids } & \multicolumn{2}{|c|}{$\mathrm{DL}$} & \multicolumn{2}{|c|}{ DM } & \multicolumn{2}{|c|}{$\mathrm{DH}$} & \multicolumn{2}{|c|}{ DHE } \\
\hline & Mean & SD & Mean & SD & Mean & SD & Mean & SD \\
\hline $14: 0$ & $1.54^{\mathrm{a}}$ & 0.12 & $1.75^{\mathrm{a}}$ & 0.03 & $1 \cdot 26^{\mathrm{b}}$ & 0.02 & $1.22^{b}$ & 0.02 \\
\hline $16: 0$ & $11 \cdot 47^{\mathrm{a}}$ & 0.67 & $22 \cdot 07^{\mathrm{b}}$ & 0.92 & $14 \cdot 25^{\mathrm{c}}$ & 0.36 & $13 \cdot 07^{\mathrm{a}, \mathrm{c}}$ & 0.66 \\
\hline $18: 0$ & $2 \cdot 92^{\mathrm{a}}$ & 0.26 & $4 \cdot 17^{\mathrm{b}}$ & 0.07 & $2.99^{a}$ & 0.43 & $3 \cdot 17^{a}$ & 0.10 \\
\hline $18: 1 n-9$ & $40 \cdot 61^{a}$ & 0.95 & $16 \cdot 66^{\mathrm{b}}$ & 0.43 & $12 \cdot 06^{\mathrm{C}}$ & 0.44 & $12 \cdot 38^{\mathrm{C}}$ & 0.57 \\
\hline $20: 4 n-6$ & $1.33^{\mathrm{a}}$ & 0.09 & $1 \cdot 26^{a, b}$ & 0.04 & $1 \cdot 13^{a, b}$ & 0.04 & $1.09^{\mathrm{b}}$ & 0.03 \\
\hline $20: 5 n-3$ & $6 \cdot 14^{\mathrm{a}}$ & 0.50 & $5.99^{a, b}$ & 0.11 & $6 \cdot 87^{b}$ & 0.10 & $7.02^{b}$ & 0.11 \\
\hline $22: 6 n-3$ & $1.68^{\mathrm{a}}$ & 0.28 & $12 \cdot 34^{\mathrm{b}}$ & 0.24 & $27.04^{\mathrm{c}}$ & 0.71 & $27 \cdot 01^{\mathrm{c}}$ & 0.63 \\
\hline Saturated $\dagger$ & $17 \cdot 85^{\mathrm{a}}$ & 0.57 & $29.48^{\mathrm{b}}$ & 2.65 & $19.92^{a}$ & 1.64 & $18 \cdot 91^{\mathrm{a}}$ & $2 \cdot 17$ \\
\hline Monounsaturated $\ddagger$ & $60.91^{\mathrm{a}}$ & 0.79 & $33.63^{\mathrm{b}}$ & 2.96 & $28 \cdot 69^{b}$ & 2.63 & $29 \cdot 60^{\mathrm{b}}$ & 2.48 \\
\hline$n-3 \S$ & $11 \cdot 38^{\mathrm{a}}$ & 0.70 & $23 \cdot 13^{\mathrm{b}}$ & 0.77 & $39 \cdot 80^{\mathrm{C}}$ & 1.66 & $39.96^{c}$ & 1.74 \\
\hline$n-6 \|$ & $6.03^{a}$ & 0.27 & $10.91^{\mathrm{b}}$ & 0.45 & $8.65^{\mathrm{c}}$ & 0.38 & $8 \cdot 68^{\mathrm{c}}$ & 0.60 \\
\hline Lipids (\% dw) & $14 \cdot 71^{\mathrm{a}}$ & 2.56 & $18 \cdot 87^{a, b}$ & 3.33 & $19 \cdot 33^{\mathrm{b}}$ & $2 \cdot 80$ & $19 \cdot 43^{b}$ & 4.09 \\
\hline Ash (\% dw) & $2.03^{a}$ & 0.38 & $2 \cdot 00^{\mathrm{a}}$ & 0.35 & $1.79^{a}$ & 0.64 & $1.96^{a}$ & 0.50 \\
\hline Protein $(\% d w)$ & $40 \cdot 92^{a}$ & 8.24 & $42 \cdot 82^{a}$ & $7 \cdot 71$ & $52 \cdot 11^{\mathrm{a}}$ & 9.06 & $53.89^{a}$ & 9.84 \\
\hline
\end{tabular}

\footnotetext{
a,b,c Mean values with unlike superscript letters were significantly different $(P<0.05)$.

* Sampling along the rotifer feeding period every $3 \mathrm{~d}$.

†Includes 12:0, 14:0, 15:0, 16:0,17:0,18:0, 20:0, 22:0 and $24: 0$.

†Includes $14: 1 n-5,14: 1 n-7,16: 1 n-9,16: 1 n-7,16: 1 n-5,18: 1 n-9,18: 1 n-7,18: 1 n-5,20: 1 n-9,20: 1 n-7,20: 1 n-5$, $22: 1 n-11,22: 1 n-9$ and $22: 1 n-7$.

§Includes $16: 2 n-3,16: 3 n-3,16: 4 n-3,18: 3 n-3,18: 4 n-3,20: 3 n-3,20: 4 n-3,20: 5 n-3,22: 4 n-3,22: 5 n-3$ and $22: 6 n-3$ I| Includes $16: 2 n-6,18: 2 n-6,18: 3 n-6,18: 4 n-6,20: 2 n-6,20: 3 n-6,20: 4 n-6,20: 5 n-6,22: 3 n-6,22: 4 n-6$ and $22: 5 n-6$.
} 
at $34 \mathrm{dph}$ (earliest moment to determine complete mineralisation in seabream larvae), fixed and stored in buffered (10\% phosphate) formaldehyde after a light sedation with $10 \%$ clove oil solution. The experiments of the present study were designed according to the Animal Welfare Ethics Committee guidelines of Las Palmas University.

Fixed larvae were stained with alizarin red and immediately photographed and examined for the occurrence of skeletal anomalies $^{(25)}$. The different regions of the vertebral column were divided according to Boglione et al. ${ }^{(26)}$. Vertebrae were numerated from 1 to 24 using Roman numerals in a cranial to caudal direction. The presence of supernumerary vertebral bodies, and the presence of urinary calculus and anomalies different from the ones described by Boglione et al. ${ }^{(26)}$ were analysed separately. The effects of the different enriched rotifers on axial skeleton mineralisation were evaluated considering the total number of completely mineralised vertebral bodies within a larval size class (standard length).

Proximate and fatty acid composition of rotifers and larvae were analysed. Total lipids were extracted with the chloroform-methanol mixture ${ }^{(27)}$ and fatty acid methyl esters obtained by transmethylation of total lipids ${ }^{(28)}$. Fatty acid methyl esters were separated by GLC, quantified by a flame ionisation detector (GC Termo Finnigan Fucus GC; Thermo Fisher Scientific Inc.) under the conditions described in Izquierdo et $a l .{ }^{(29)}$. Crude protein, moisture and ash content were analysed following the Association of Official Analytical Chemists methods ${ }^{(30)}$. $\alpha$-Tocopherol content was analysed by HPLC. Thiobarbituric acid reactivity was determined by an adaptation of the Burk et al. ${ }^{(31)}$ method as reported in Tocher et $a l .{ }^{(32)}$. Values were expressed as $\mu \mathrm{g}$ malonaldehyde/g sample.

Total RNA was extracted from seabream larvae (approximately $200 \mathrm{mg}$; pool per tank), using the PureYield RNA Midiprep System. The quantity and purity of RNA were assessed by a spectrophotometer. Visualisation on $1 \%$ agarose gel stained with ethidium bromide showed that RNA was not degraded. After DNase treatment (Invitrogen), $3 \mu \mathrm{g}$ of total RNA were reverse transcribed into complementary DNA in a volume of $12 \mu \mathrm{l}$, including $1 \mu \mathrm{l}$ of oligo-dT16 primer ( $50 \mathrm{pmol}$ ) and $1 \mu \mathrm{l}$ of $10 \mathrm{~mm}$-deoxynucleotide triphosphates. This mix was heated at $65^{\circ} \mathrm{C}$ for $5 \mathrm{~min}$ and chilled on ice, and then $4 \mu \mathrm{l}$ of $5 \times$ reverse transcription buffer, $2 \mu \mathrm{l}$ of $0 \cdot 1 \mathrm{M}$-dithiothreitol, $1 \mu \mathrm{l}$ RNase out and $1 \mu \mathrm{l}$ of Moloney murine leukaemia virus were added. After incubation at $37^{\circ} \mathrm{C}$ for $50 \mathrm{~min}$, the reaction was stopped by heating at $75^{\circ} \mathrm{C}$ for $15 \mathrm{~min}$. The PCR primer sequences used for the PCR amplification of complementary DNA of target genes such as CAT, SOD, GPX and IGF-1 are shown in Table 3. A total of thirty PCR amplification cycles (eight touchdown) were performed for all primer sets, using an automated thermal cycler (MyCycler; BioRad). An aliquot of each sample was then electrophoresed on $1 \%$ agarose gel and bands were detected by ethidium bromide staining. The PCR products from each primer set amplification were cloned using the pGEM ${ }^{\circledR}$-T Easy Vector (Promega) and subsequently sequenced in both directions (T7 and SP6). TaqMan ${ }^{\circledR}$ real-time RT-PCR was performed on a StepOne Real Time PCR System (Applied Biosystems) using Assays-by-Design ${ }^{\text {SM }}$ PCR primers (Applied Biosystems) 
and gene-specific fluorogenic probes (Table 3). Data from TaqMan $^{\circledR}$ PCR runs were collected with ABI's Sequence Detector Program. Cycle threshold $\left(C_{\mathrm{t}}\right)$ values corresponded to the number of cycles at which fluorescence emission monitored in real time exceeded the threshold limit. The $C_{\mathrm{t}}$ values were used to create standard curves to serve as a basis for calculating the absolute amounts of mRNA in total RNA. To reduce pipetting errors, master mixes were prepared to set up triplicate reactions $(3 \times 30 \mu \mathrm{l})$ for each sample.

All values presented as percentage (skeletal anomalies, mineralisation of the column, total survival and survival after the activity test) were arc cosine transformed. Statistical differences were checked with one-way ANOVA for multiple comparisons of means. In the case of statistical differences among the treatment groups, a Duncan post hoc test was applied in order to evaluate inter-group differences. If variances were not homogeneous, a parametric test was applied (homogeneity of the variance with Levene's test, data normality with Shapiro-Wilk test). The significance level was fixed at 95\%.

\section{Results}

The proximate composition of rotifers enriched with the different DHA and $\alpha$-tocopherol levels was not significantly different in terms of crude protein and ash content ( $P>0.05$; Table 2$)$. However, the lipid content was lower in rotifers fed the lowest DHA level (DL rotifers; $P<0.05$ ) than in those fed the highest DHA level (DH and DHE rotifers) (Table 2). Regarding the fatty acid profiles (Table 2), DL rotifers showed the lowest $(P<0.05)$ DHA contents $(0 \cdot 25 \% \mathrm{dw})$, together with lower $n-3$, $n-6$ and SFA, particularly $16: 0$ and 18:0. On the contrary, these rotifers showed the highest percentage of MUFA, mainly oleic acid (18: $1 n-9)$. DM rotifers showed medium contents of DHA levels $(2 \cdot 39 \% \mathrm{dw})$ and the highest percentages of SFA, principally myristic $(14: 0)$, palmitic $(16: 0)$ and stearic $(18: 0)$ acids (Table 2). Rotifers fed the highest DHA level (DH and DHE rotifers) showed significantly $(P<0.05)$ higher levels of DHA $(5 \cdot 2 \% \mathrm{dw})$ than DL and DM rotifers. Thus, an increase in DHA content in the enrichment products proportionally raised the DHA content in rotifers $(R 0.96, P<0.05)$.

Lipid contents in $15 \mathrm{dph}$ larvae were about $14 \% \mathrm{dw}$, being slightly higher in fish fed the highest DHA content (DH larvae) (Table 4). Crude protein and ash contents were significantly lowest in seabream fed DL rotifers. Regarding the fatty acid profiles (Table 4), while the total content of SFA was similar among larvae fed the different types of rotifers, monoenoic acid contents were significantly highest in DL fish, principally due to a higher percentage of oleic acid (18:1n-9). As expected, total $n-3$ fatty acids and, particularly, DHA contents were significantly lowest in DL larvae, gradually increasing in DM, DH and DHE larvae as a consequence of higher dietary DHA levels. Thus, a significant correlation between the DHA content in total lipids of rotifers and larvae was found $(y=0.4502 x+1 \cdot 1023$, $R^{2}$ 0.9182). The degree of lipid oxidation in larval tissues, expressed as the malonaldehyde content $(\mu \mathrm{mol} / \mathrm{g})$ in gilthead seabream, was proportionally increased with the elevation of DHA in rotifers, the significantly lowest peroxidation level $(P<0.05)$ being found in DL and DHE larvae (Table 4).

Survival of larvae from hatching until metamorphosis at $34 \mathrm{dph}$ did not significantly differ among larvae fed the different enriched rotifers, being on average $22 \%$ very good for this type of trial and similar to that obtained by commercial hatcheries of this species. There were no significant differences in rotifer ingestion, swim bladder inflation or survival

Table 4. Proximate (\% dry weight $(\mathrm{dw}))$ and fatty acid $(\% \mathrm{dw})$ composition from total lipids and thiobarbituric acid-reactive (TBAR) contents of gilthead seabream larvae (15d post-hatching) fed rotifers containing low (DL), medium (DM) or high (DH) levels of DHA and high DHA levels with an extra supplement of $\alpha$-tocopherol (DHE)

(Mean values and standard deviations, $n$ 2)

\begin{tabular}{|c|c|c|c|c|c|c|c|c|}
\hline \multirow[b]{2}{*}{ Fatty acids } & \multicolumn{2}{|c|}{$\mathrm{DL}$} & \multicolumn{2}{|c|}{$\mathrm{DM}$} & \multicolumn{2}{|c|}{$\mathrm{DH}$} & \multicolumn{2}{|c|}{ DHE } \\
\hline & Mean & $\mathrm{SD}$ & Mean & $\mathrm{SD}$ & Mean & SD & Mean & $S D$ \\
\hline $14: 0$ & $0 \cdot 20^{a}$ & 0.02 & $0.12^{b}$ & 0.01 & $0.13^{b}$ & 0.06 & $0 \cdot 13^{b}$ & 0.01 \\
\hline $16: 0$ & $2.43^{\mathrm{a}}$ & 0.29 & $2 \cdot 28^{a}$ & 0.02 & $2 \cdot 37^{a}$ & 0.13 & $2 \cdot 41^{\mathrm{a}}$ & 0.12 \\
\hline $18: 0$ & $1 \cdot 18^{a}$ & 0.08 & $1 \cdot 11^{a}$ & 0.04 & $1 \cdot 29^{a}$ & 0.15 & $1 \cdot 17^{\mathrm{a}}$ & 0.02 \\
\hline $18: 1 n-9$ & $2.09^{a}$ & 0.19 & $1 \cdot 66^{a, b}$ & 0.32 & $1 \cdot 76^{a, b}$ & 0.22 & $1 \cdot 35^{b}$ & 0.15 \\
\hline $20: 4 n-6$ & $0.55^{a}$ & 0.03 & $0.48^{\mathrm{a}}$ & 0.04 & $0.51^{a}$ & 0.03 & $0.48^{a}$ & 0.05 \\
\hline $20: 5 n-3$ & $1.47^{\mathrm{a}}$ & 0.18 & $1 \cdot 14^{b}$ & 0.09 & $1 \cdot 31^{\mathrm{a}, \mathrm{b}}$ & 0.13 & $1 \cdot 22^{\mathrm{a}, \mathrm{b}}$ & 0.11 \\
\hline $22: 6 n-3$ & $0.97^{a}$ & 0.11 & $2.49^{b}$ & 0.41 & $3 \cdot 62^{c}$ & 0.34 & $3 \cdot 12^{c}$ & 0.18 \\
\hline Saturated $\dagger$ & $4.02^{a}$ & 0.38 & $3 \cdot 72^{a}$ & 0.16 & $4.02^{a}$ & 0.11 & $3.93^{a}$ & 0.02 \\
\hline Monoenoic & $4 \cdot 37^{a}$ & 0.26 & $3.56^{b}$ & 0.22 & $3.63^{b}$ & 0.29 & $3 \cdot 24^{b}$ & 0.18 \\
\hline$n-3 \S$ & $3 \cdot 34^{a}$ & 0.41 & $4 \cdot 46^{b}$ & 0.60 & $5 \cdot 80^{c}$ & 0.25 & $5 \cdot 35^{\mathrm{b}, \mathrm{c}}$ & 0.50 \\
\hline$n-6 \|$ & $1 \cdot 32^{\mathrm{a}}$ & 0.51 & $1 \cdot 36^{a}$ & 0.10 & $1.41^{\mathrm{a}}$ & 0.50 & $1 \cdot 18^{a}$ & 0.16 \\
\hline Crude lipids (\% dw) & $13 \cdot 39^{a}$ & 0.99 & $13 \cdot 53^{a}$ & 0.93 & $15 \cdot 63^{a}$ & $1 \cdot 26$ & $14 \cdot 03^{a}$ & 0.75 \\
\hline Ash (\% dw) & $1.47^{\mathrm{a}}$ & 0.05 & $1.96^{\mathrm{c}}$ & 0.05 & $1.97^{\mathrm{b}, \mathrm{c}}$ & 0.32 & $1 \cdot 53^{a, b}$ & 0.24 \\
\hline Protein $(\% \mathrm{dw})$ & $73 \cdot 86^{a}$ & $2 \cdot 12$ & $77 \cdot 38^{b}$ & $2 \cdot 86$ & $75 \cdot 85^{\mathrm{b}}$ & 3.97 & $77 \cdot 90^{\mathrm{b}}$ & 2.88 \\
\hline TBAR ( $\mu \mathrm{g}$ malonaldehyde/g) & $0.20^{\mathrm{a}}$ & 0.04 & $8.93^{b}$ & $1 \cdot 20$ & $11 \cdot 04^{b}$ & 1.50 & $0.23^{a}$ & 0.06 \\
\hline
\end{tabular}

${ }^{\mathrm{a}, \mathrm{b}, \mathrm{c}}$ Mean values with unlike superscript letters were significantly different $(P<0.05)$.

$\dagger$ Includes 12:0, 14:0, 15:0,16:0,17:0,18:0,20:0,22:0 and $24: 0$.

łIncludes $14: 1 n-5,14: 1 n-7,16: 1 n-9,16: 1 n-7,16: 1 n-5,18: 1 n-9,18: 1 n-7,18: 1 n-5,20: 1 n-9,20: 1 n-7,20: 1 n-5,22: 1 n-11,22: 1 n-9$ and $22: 1 n-7$.

§Includes $16: 2 n-3,16: 3 n-3,16: 4 n-3,18: 3 n-3,18: 4 n-3,20: 3 n-3,20: 4 n-3,20: 5 n-3,22: 4 n-3,22: 5 n-3$ and $22: 6 n-3$.

|| Includes $16: 2 n-6,18: 2 n-6,18: 3 n-6,18: 4 n-6,20: 2 n-6,20: 3 n-6,20: 4 n-6,20: 5 n-6,22: 3 n-6,22: 4 n-6$ and $22: 5 n-6$. 
after the activity test (85\%). Regarding growth, during the first 2 weeks of pure rotifer diet, the total length of larvae increased proportionally to the DHA levels of rotifers (mean total length: DL 4.78 (sD 0.34), DM 4.97 (SD 0.53), DH 5.02 (SD 0.26) and DHE $5 \cdot 15$ (SD 0.22), $P<0.05, n$ 120). Nevertheless, lipid and, hence, gross energy contents were also increased in rotifers with higher DHA levels. Once Artemia and the weaning diet were fed to all larvae, growth became similar among the treatments and, thus, no significant differences among larvae were observed at the end of the trial (Fig. 1). Trend curves of the standard length increase in larvae fed rotifers with the lowest DHA content (DL) reflected the lowest growth in these larvae. Similar trends were also found in larval dry body weight, which, at $34 \mathrm{dph}$, reached 0.92 (SD 0.24), 1.20 (sD 0.27), 1.22 (sD 0.32) and 1.16 (sD 0.25) $\mathrm{mg}$ for DL, DM, DH and DHE larvae, respectively.

The lowest occurrence of total skeletal deformities was found in larvae fed DM rotifers $(P<0.05)$ (Table 5). Either the reduction of DHA contents in DL rotifers or its increase in $\mathrm{DH}$ rotifers significantly raised the percentage of total anomalies (Table 5). The types of deformities differed according to the level of DHA. Thus, DL larvae showed significant increases in the occurrence of lordosis and kyphosis (cranial-pre-haemal $v$. II-III vertebrae or haemal $v$. XX-XXI vertebrae) in comparison with DM larvae. Concurrently, $\mathrm{DH}$ larvae showed a significantly higher incidence of maxillary or mandibular anomalies (maxillary prognatism), as well as a higher occurrence of haemal or neural spine abnormalities (curled, wrong directed or bifurcated, frequently in cranial ( $v$. II), pre-haemal $(v$. V) or haemal vertebrae). On the contrary, increasing $\alpha$-tocopherol contents in DHE rotifers significantly reduced the occurrence of total deformities

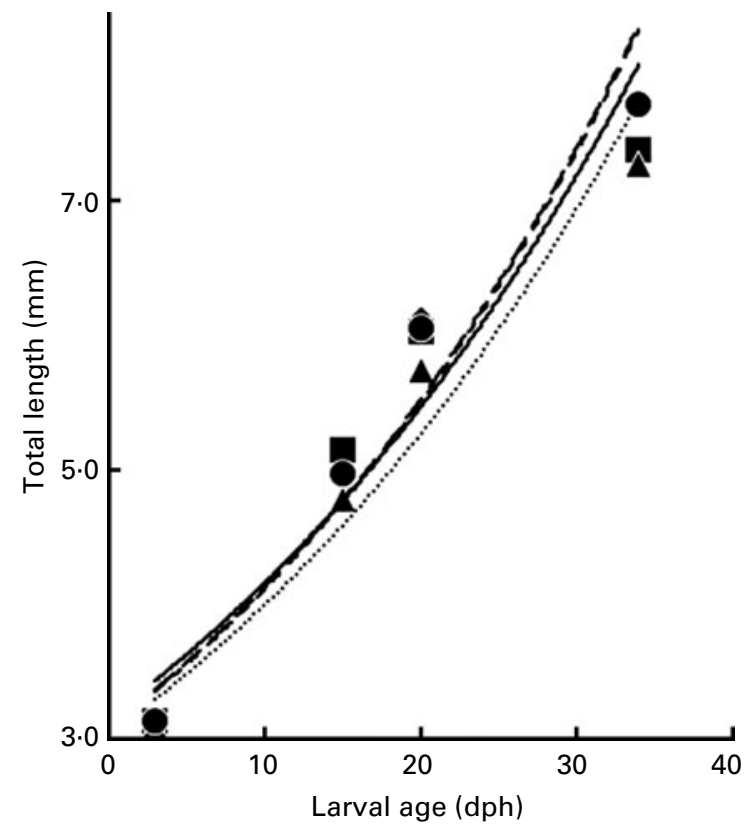

Fig. 1. Development of the standard length of gilthead seabream fed rotifers low (DL, $\boldsymbol{\Delta} ; y=3.1619 \mathrm{e}^{0.0274 x}, R^{2}$ 0.92325), medium (DM, •; $\left.y=3.0722 \mathrm{e}^{0.0292 x}, R^{2} 0.95291\right)$ or high $\left(\mathrm{DH}, \diamond ; y=3.083 \mathrm{e}^{0.0292 x}, R^{2}\right.$ $0.94394)$ in DHA and high in DHA with an extra supplement of $\alpha$-tocopherol (DHE, $\left.\mathbf{\square} ; y=3.0317 \mathrm{e}^{0.0276 x}, R^{2} 0.95628\right)(n 90)$. dph, Days post-hatching. in DHE larvae in comparison with DH larvae (Table 5). Thus, the incidence of both maxillary/mandibular or haemal/neural spines in DHE larvae was similar to that in DM larvae. Opercular anomalies were found only in one specimen.

Marked differences among larvae fed the different types of rotifers were also found regarding the mineralisation of the vertebral centra (Fig. 2). Since the number of mineralised centra increased with larval growth, the number of mineralised vertebrae in the different larval groups was compared within the size classes (Fig. 2). For each given size class between 6 and $9 \mathrm{~mm}$, DL larvae always showed a significantly ( $\left.F=6.11>F_{\text {crit }}=2.54, T=2.36\right)$ lower number of mineralised vertebrae, whereas the elevation of dietary DHA (DM, DH and DHE larvae) markedly increased mineralisation (Fig. 2). In particular, from 7.085 up to $8.085 \mathrm{~mm}$ standard length, larvae from the DHE group showed twenty completely mineralised vertebral centra, whereas the reduction in dietary $\alpha$-tocopherol in $\mathrm{DH}$ larvae limited this number to seventeen to twenty. The reduction in dietary DHA in DM and DL larvae further decreased the number of completely mineralised vertebrae to fourteen to twenty and ten to twenty, respectively. As a consequence, the size at which all larvae had completed the mineralisation of the vertebral column was delayed until $9.09 \mathrm{~mm}$ standard length in DL larvae, in comparison with larvae fed higher DHA (8.58 mm in DM and DH larvae) or $\alpha$-tocopherol ( $8.09 \mathrm{~mm}$ standard length in DHE larvae). Although the presence of calculi in the urinary bladder of gilthead seabream did not significantly differ among the treatments, the highest value was found in fish fed the DHAdeficient diet $(9.3 \%$ of the population) in comparison with those larvae fed DHA-enriched rotifers $(2 \cdot 0,5 \cdot 3$ and $0.7 \%$ for DM, DH and DHE, respectively).

Regarding the expression of the target genes (Fig. 3), the $I G F-1$ mRNA copy number significantly increased with the elevation of dietary DHA. On the contrary, in comparison with larvae fed the highest DHA content (DH), those fed higher dietary $\alpha$-tocopherol showed a significantly reduced expression of IGF-1 mRNA. The expression of the CAT gene tended to increase proportionally to the elevation of DHA contents in rotifers, although no significant differences were found among these values (Fig. 4). However, the increase in dietary $\alpha$-tocopherol significantly reduced the expression of both CAT and SOD genes (Fig. 4), whereas the elevation of dietary vitamin $\mathrm{E}$ led to an increase in the number of mRNA copies of GPX in larvae fed the DHE diet (Fig. 4).

\section{Discussion}

The contents in essential arachidonic acid (20:4n-6) and EPA $(20: 5 n-3)$ in all the enriched rotifers (over 0.2 and $0.9 \% \mathrm{dw}$, respectively) were enough to cover the requirements of gilthead seabream larvae for these fatty acids ${ }^{(33)}$. Additionally, DHA levels in rotifers enriched with DHA (2-5\% dw in DM, $\mathrm{DH}$ and DHE rotifers) were also higher than the minimum requirement determined for this species $^{(34,35)}$. However, rotifers containing the lowest DHA levels (0.25\% dw in DL) represent a deficient diet in this fatty acid. They contained 
Table 5. Percentage of larvae bearing each skeletal anomaly (\% of total fish) and the sum of these incidences (total anomalies) in $34 \mathrm{~d}$ post-hatching (dph) gilthead Seabream after feeding from 2 to 25 dph with rotifers low (DL), medium (DM) or high (DH) in DHA and high in DHA with an extra supplement of $\alpha$-tocopherol (DHE)

(Mean values and standard deviations, $n 150$ )

\begin{tabular}{|c|c|c|c|c|c|c|c|c|c|c|c|c|}
\hline \multirow[b]{2}{*}{ Dietary treatments } & \multicolumn{2}{|c|}{$\begin{array}{c}\text { Total } \\
\text { anomalies }\end{array}$} & \multicolumn{2}{|c|}{ Lordosis } & \multicolumn{2}{|c|}{ Kyphosis } & \multicolumn{2}{|c|}{ Fusions } & \multicolumn{2}{|c|}{$\begin{array}{c}\text { Maxilla/ } \\
\text { mandible }\end{array}$} & \multicolumn{2}{|c|}{$\begin{array}{l}\text { Haemal/- } \\
\text { neural spine } \\
\text { anomalies }\end{array}$} \\
\hline & Mean & SD & Mean & SD & Mean & SD & Mean & SD & Mean & SD & Mean & SD \\
\hline DL & $9 \cdot 3^{\mathrm{a}}$ & 1.6 & $4 \cdot 6^{\mathrm{a}}$ & 3.6 & $2 \cdot 0^{\mathrm{a}}$ & $1 \cdot 1$ & 0.7 & 0.6 & $0.7^{\mathrm{a}}$ & 0.6 & $1.3^{\mathrm{a}}$ & 1.2 \\
\hline $\mathrm{DM}$ & $4.0^{b}$ & 0.8 & $1 \cdot 0^{\mathrm{b}}$ & 0.9 & \multicolumn{2}{|c|}{ ND } & \multicolumn{2}{|c|}{ ND } & $1 \cdot 0^{\mathrm{a}}$ & 0.9 & $2 \cdot 0^{\mathrm{a}}$ & 0.1 \\
\hline $\mathrm{DH}$ & $10 \cdot 3^{a}$ & 1.4 & $1.4^{\mathrm{b}}$ & 1.2 & $0.7^{\mathrm{b}}$ & 0.6 & 0.7 & 0.6 & $4 \cdot 1^{\mathrm{b}}$ & 3.7 & $2 \cdot 7^{\mathrm{a}}$ & $1 \cdot 1$ \\
\hline $\mathrm{DHE}$ & $7 \cdot 6^{c}$ & 0.5 & $1 \cdot 4^{\mathrm{b}}$ & 1.2 & $0.7^{b}$ & 0.6 & 1.4 & 1.2 & $2 \cdot 0^{\mathrm{a}, \mathrm{b}}$ & 1.2 & $1 \cdot 4^{a}$ & 1.2 \\
\hline
\end{tabular}

ND, not detected.

${ }^{\mathrm{a}, \mathrm{b}, \mathrm{c}}$ Mean values within a column with unlike superscript letters were significantly different $(P<0.05)$

only $31 \%$ of DHA required by gilthead seabream larvae $(0 \cdot 8 \%$ $\mathrm{dw})^{(36)}$. Among the different essential fatty acids, DHA appears to be the most effective larval growth promoter. Its incorporation into larval tissues affects intercellular interaction, receptor expression, nutrient transport and signal transduction, all of which affect cell growth ${ }^{(33)}$. Accordingly, in the present study, larval growth tended to be lower when fish were fed DL rotifers with only $0.25 \%$ DHA content. These fish also presented the lowest IGF-1 gene expression. Moreover, these fish showed a higher incidence of lordosis and kyphosis, possibly a consequence of poor mineralisation found in these larvae. Similar types of anomalies in adult fish appear to result from inadequate adaptation of individual vertebrae to muscular load ${ }^{(37)}$. In other vertebrates, an essential fatty acid deficiency has been associated with a reduction in bone mineralisation and increased renal calcification ${ }^{(38)}$. The presence of calculi in the urinary bladder of gilthead seabream, observed in the present study, was highest in fish fed the DHA-deficient diet, although the differences were not statistically different from the other fish. The present results are in agreement with those found in mice, where increased DHA levels reduced the presence of renal calculi( ${ }^{(39)}$. Moreover,

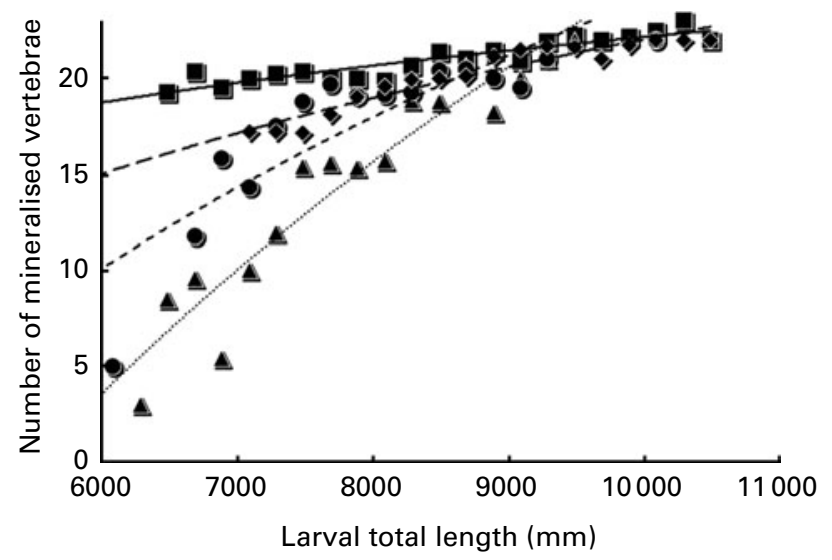

Fig. 2. Number of mineralised vertebrae per larvae of each size class of gilthead seabream (34d post-hatching (dph)) fed from 3 to 25 dph rotifers low (DL, $\boldsymbol{\Delta} ; y=42.096 \ln (x)-362.68, R^{2} 0.90783$ ), medium (DM, @; $\left.y=27.511 \ln (x)-229.27, \quad R^{2} 0.74658\right)$ or high $(\mathrm{DH}$, $\left.y=13.777 \ln (x)-104.85, R^{2} 0.91801\right)$ in DHA or high in DHA with an extra supplement of $\alpha$-tocopherol (DHE, $\mathbf{\square} ; y=6.7165 \ln (x)-39.698$, $\left.R^{2} 0.84637\right)$
DHA has been found to increase bone mineral content and bone mass in other vertebrates ${ }^{(38,39)}$. Accordingly, together with the lowest number of mineralised vertebrae, gilthead seabream larvae fed the lowest DHA level also presented a lower mineral content reflected in the lowest ash quantity in these larvae. In addition to the important role of DHA for mineral metabolism across biomembranes, this fatty acid seems to be required for bone formation, which is regulated by systemic hormones and local factors produced in bone such as eicosanoids ${ }^{(40)}$ and, probably, docosanoids. Docosanoids are mono-, di- and trihydroxylated derivatives of DHA including docosatrienes, protectins and the D-series resolvins $^{(41)}$. In gilthead seabream, lipoxygenase derivatives from DHA have been found to regulate cell responses in the kidney ${ }^{(42,43)}$. In turn, these compounds influence the synthesis and action of IGF, growth factors also produced locally in bones $^{(44)}$ that promote cell proliferation and differentiation ${ }^{(45)}$. Accordingly, in the present study, IGF-1 expression was the lowest in larvae fed the lowest DHA level. These larvae also showed the lowest growth. The increase in DHA has also been associated with higher IGF-1 expression in European seabass (D. labrax $)^{(13)}$. IGF-1 acts as a regulator of bone cell function, as it stimulates the proliferation of pre-osteoblasts, thereby increasing the number of cells capable of producing the bone matrix ${ }^{(38)}$. Consequently, the enhanced mineralisation effect of increased DHA could be at least partly mediated by

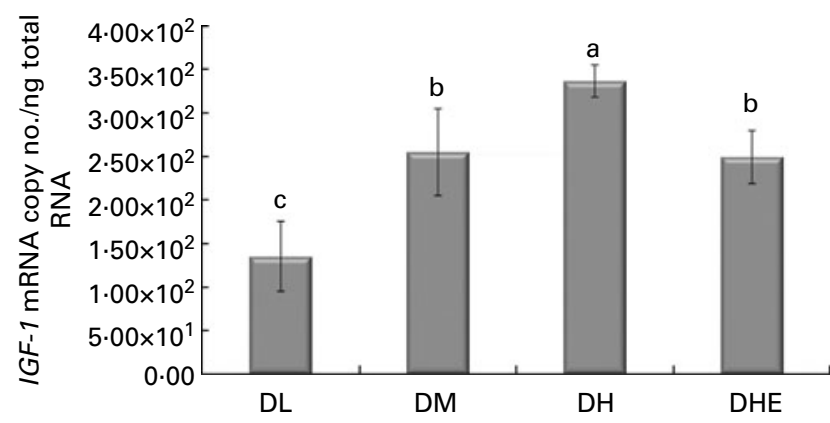

Fig. 3. Insulin growth factor 1 (IGF-1) gene expression levels measured by real-time PCR in Sparus aurata larvae (15d post-hatching) fed exclusively rotifers low (DL), medium (DM) or high (DH) in DHA or high in DHA with an extra supplement of $\alpha$-tocopherol (DHE). mRNA copy number of each gene was normalised as a ratio to $100 \mathrm{ng}$ total RNA. Values are means $(n 8)$, with their standard deviations represented by vertical bars. ${ }^{a, b, c}$ Mean values with unlike letters were significantly different $(P<0.05)$. 
(A)

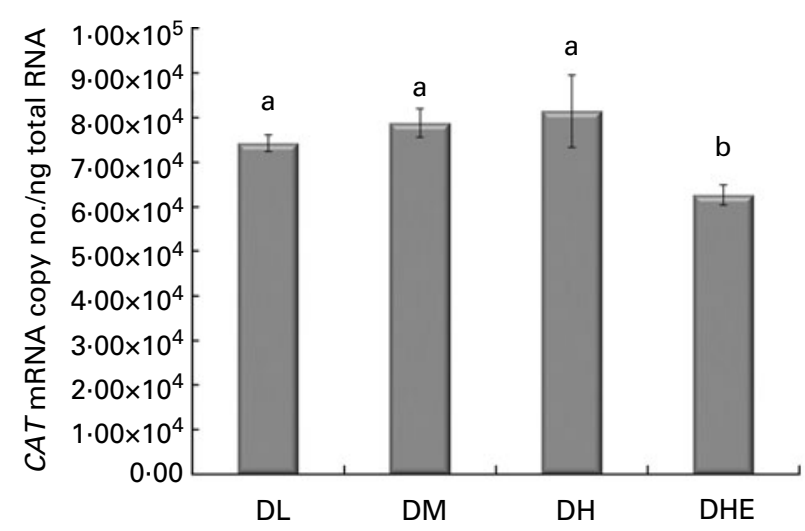

(C)
(B)

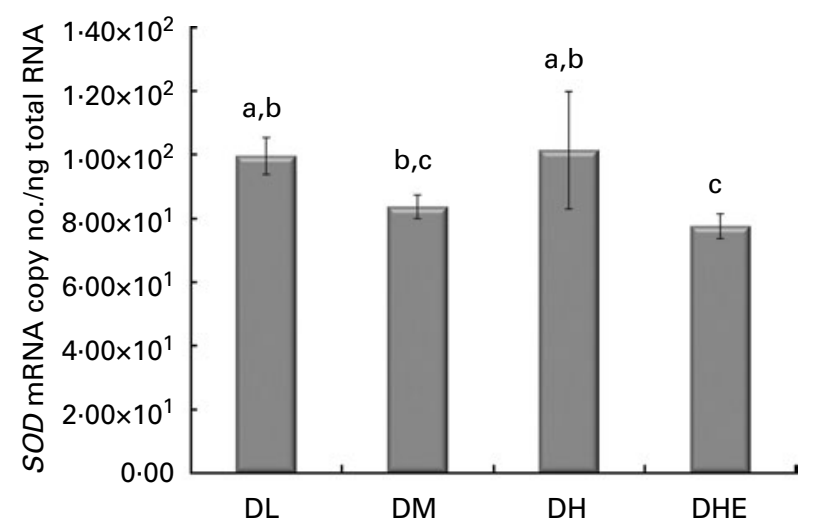

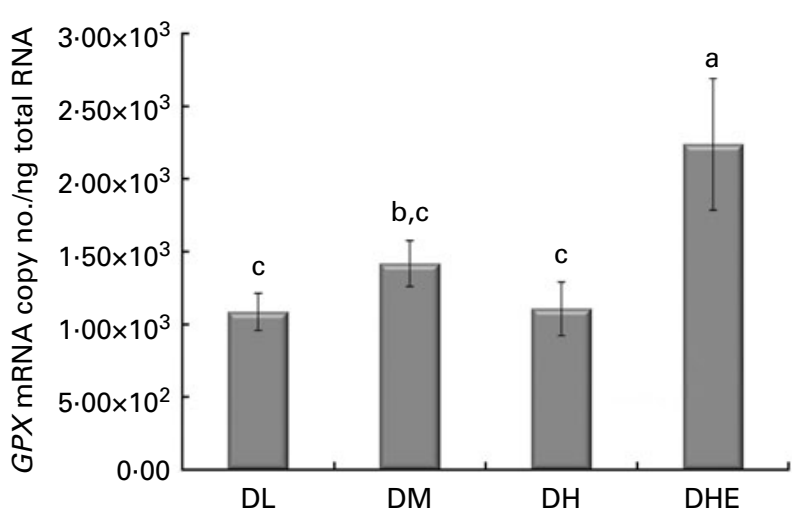

Fig. 4. Gene expression of $(A)$ catalase $(C A T)$, (B) superoxide dismutase $(S O D)$ and $(C)$ glutathione peroxidases $(G P X)$ measured by real-time $P C R$ in $S p a r u s$ aurata larvae (15d post-hatching) fed exclusively rotifers either low (DL), medium (DM) or high (DH) in DHA or high in DHA with an extra supplement of $\alpha$-tocopherol (DHE). mRNA copy number of each gene was normalised as a ratio to $100 \mathrm{ng}$ total RNA. Values are means ( $n$ 8), with their standard deviations represented by vertical bars. ${ }^{a, b, c}$ Mean values with unlike letters were significantly different $(P<0.05)$.

the significant up-regulation of IGF-1 found in the present study. Deficiencies in essential fatty acids, including DHA, have also been related to a reduction in the synthesis of the bone connective tissue matrix ${ }^{(46)}$ and to the expression of osteogenic markers such as osteocalcin ${ }^{(47)}$.

The increase in dietary DHA levels up to $2 \%$ (DM rotifers) significantly reduced the number of total deformed larvae, including lordosis and kyphosis, even below the mean frequency of abnormalities reported in gilthead seabream hatcheries $(7-20 \%)^{(48)}$. However, further elevation of DHA up to $5 \%$ increased the maxillary/mandibular deformity occurrence. The detrimental effects of excessive dietary DHA have also been found in European sea bass, where severe dystrophic lesions in the epaxial musculature were observed ${ }^{(13,49)}$. An increase of both DHA and EPA in phospholipids of sea bass increased skeletal abnormalities and larval mortality ${ }^{(12)}$. However, an $8 \mathrm{~h}$ enrichment with the type of emulsions used in the present study increases mostly the DHA contents in the neutral lipid fraction rather than in the phospholipid fraction as demonstrated in previous studies ${ }^{(6)}$, denoting the specific effect of dietary DHA, independently of EPA or phospholipid dietary levels. Thus, the elevation of dietary DHA markedly raises the risk of peroxidation and the subsequent proliferation of free radicals and toxic oxidised compounds such as fatty acid hydroxyperoxides, fatty acid hydroxides, aldehydes and hydrocarbons. The latter may be toxic and damage membrane lipids, proteins or $\mathrm{DNA}^{(33)}$. Free radicals and oxidation products have been found to induce apoptosis of mammalian bone cells. Interestingly, the increase in dietary DHA, together with an increased oxidative status of larvae, was associated with particular deformities. In the cranium, namely maxilla and mandible were affected. In the axial skeleton, haemal and neural spines were observed to be deformed. All these skeletal elements develop from a cartilaginous precursor in seabream. In contrast, skeletal elements without a cartilaginous precursor, such as the vertebral centra, were not negatively affected. Indeed, reactive oxygen species are known to actively destroy cartilaginous tissue ${ }^{(50)}$, and therefore they rather affect the cartilaginous anlagen of endochondral bones than the directly mineralising acellular (anosteocytic) seabream bones.

To prevent oxidative damage, a range of effective antioxidant systems including various antioxidant enzymes, such as CAT, SOD or GPX, intercept and inactivate reactive intermediates, preventing the cascade of oxidant reactions. Together with these enzymes, dietary micronutrients such as $\alpha$-tocopherol or vitamin $\mathrm{C}$ complete antioxidant defences in fish. Moreover, an increase in the formation of free radicals that derive from PUFA in larval tissues that would not be accompanied by an increase in $\alpha$-tocopherol would reduce 
the availability of ascorbic acid that recycles the oxidised $\alpha$-tocopherol. Vitamin C is an essential cofactor for collagen formation, and hence a lack of vitamin $\mathrm{C}$ causes bone deformities in teleost fish ${ }^{(51)}$. In the present study, increased $\alpha$-tocopherol in high DHA enrichments reduced the occurrence of jaw deformities and of haemal and neural spine deformities in comparison with fish fed high DHA without $\alpha$-tocopherol supplementation $(\mathrm{DH})$. The progressive increase in the expression of specific antioxidant genes, such as CAT and $S O D$, to neutralise the generated reactive oxygen substances was significantly reduced in larvae fed higher $\alpha$-tocopherol (DHE), denoting the protective effect of $\alpha$-tocopherol against oxidative stress. Indeed, the activities of these two enzymes would be expected to parallel each other, since superoxide anions are efficiently scavenged by $\alpha$-tocopherol in biological systems. Although both GPX and CAT remove $\mathrm{H}_{2} \mathrm{O}_{2}$, GPX is more involved in the removal of organic peroxides. Disruptions in the expression of several antioxidant enzymes in fish larvae exposed to increased dietary DHA have recently been described in European sea bass ${ }^{(13)}$. These results further suggest that the type of skeletal deformities caused by high dietary DHA is related to the increased oxidative risk in larvae that damages the cartilage anlagen of endochondral bones. Besides, optimum DHA levels may also be dependent on dietary levels of other nutrients ${ }^{(52)}$. Finally, the increase in dietary $\alpha$-tocopherol was also associated with a significant reduction in IGF-1, further supporting the suggestion that oxidative stress may play a role in the expression of these growth factors ${ }^{(13)}$. Nevertheless, studies on the effects of $\alpha$-tocopherol on fish musculoskeletal development or malformation are scarce. The subject of malformations that are associated with oxidised lipids ${ }^{(19)}$ or high levels of PUFA ${ }^{(49,52)}$ deserves further investigation.

In summary, the results of the present study denote the importance of feeding amounts of dietary DHA during the first feeding of gilthead seabream larvae to better control the occurrence of skeletal anomalies. Early feeding of an adequate DHA diet is important, even if survival or growth is promoted later in development by feeding adequate DHA levels in Artemia and inert diets. Feeding low-DHA rotifers can delay early mineralisation and thus increase the risk of cranial and axial skeletal deformities as a consequence of the natural mechanical load that derives from swimming and feeding. On the other hand, feeding highDHA rotifers, without an adequate balance of antioxidant nutrients, may increase the production of free radicals that damage the cartilaginous anlagen of bones and thus favour the development of skeletal deformities.

\section{Acknowledgements}

Acknowledgement is due to the valuable comments of an anonymous referee. M. S. I. conceived the study and its design, coordinated the work and the interpretation of the results and wrote the manuscript. M. S. carried out the animal experiment, performed the biochemical studies and bone staining and participated in the interpretation of the results. M. B. and G. T. performed the molecular studies. J. R. participated in the experimental design of the diets and the interpretation of the results. M. J. C. supervised the bone staining studies. P. E. W. participated in the design of the study and the interpretation of the results. All the authors read and approved the final manuscript. There are no potential conflicts of interest and this research was funded by the first author's own budget for research.

\section{References}

1. Lewis-McCrea M \& Lall SP (2007) Effects of moderately oxidized dietary lipid and the role of vitamin $\mathrm{E}$ on the development of skeletal abnormalities in juvenile Atlantic halibut (Hippoglossus hippoglossus). Aquaculture 262, 142-155.

2. Satoh S, Poe WE \& Wilson RP (1989) Effect of supplementation of phytate and/or 3-calcium phosphate on wet gain, feed efficiency and zinc content in vertebrae of channel catfish. Aquaculture 80, 155-161.

3. Takeuchi $\mathrm{T}$ (1999) Mechanism and prevention of color abnormality in flounder. Aquanet 2, 48-52.

4. Takeuchi T, Dedi J, Haga Y, et al. (1998) Effect of vitamin A compounds on bone deformity in larval Japanese flounder Paralichthys olivaceus. Aquaculture 169, 155-165.

5. Cahu CL, Zambonino Infante JL \& Barbosa V (2003) Phospholipid level in dietary lipid fraction is determining for sea bass (Dicentrarchus labrax) larval development. $\mathrm{Br} J$ Nutr 90, 21-28.

6. Izquierdo MS (1988) Essential fatty acid requirements of marine fish larvae: modification of live prey lipid composition. PhD Thesis, La Laguna University, Spain, 205 pp.

7. Roo FJ (2009) Improvement in the production technology of red porgy (Pagrus pagrus) larvae and fry: importance of rearing conditions and diet nutritional value on their quality. PhD Thesis, Universidad de Las Palmas de Gran Canaria, Spain.

8. Lewis-McCrea LM \& Lall SP (2010) Effects of phosphorus and vitamin $\mathrm{C}$ deficiency, vitamin A toxicity, and lipid peroxidation on skeletal abnormalities in Atlantic halibut (Hippoglossus hippoglossus). J App Ichthyol 26, 334-343.

9. Kanazawa A, Teshima S, Inamori S, et al. (1981) Effects of phospholipids on growth, survival rate and incidence of malformation in the larval ayu. Mem Fac Fish Kagoshima Univ 30, 301-309.

10. Izquierdo MS, Socorro J \& Roo J (2010) Studies on the appearance of skeletal anomalies in red porgy: effect of culture intensiveness, feeding habits and nutritional quality of live preys. J App Ichthyol 26, 320-326.

11. Gapasin R \& Duray M (2001) Effects of DHA-enriched live food on growth, survival and incidence of opercular deformities in milkfish (Chanos chanos). Aquaculture 193, 49-63.

12. Villeneuve L, Gisbert E, Zambonino Infante JL, et al. (2005) Effect of nature of dietary lipids on European sea bass morphogenesis: implication of retinoid receptors. Br J Nutr 94, 877-884.

13. Betancor M, Caballero MJ, Terova G, et al. (2012) Selenium inclusion decreases oxidative stress indicators and muscle injuries in sea bass larvae fed high DHA microdiets. BrJ Nutr 108, 2115-2128.

14. Zhang X, Xie P, Li D, et al. (2009) Time-dependent oxidative stress responses of crucian carp (Carassius auratus) to intraperitoneal injection of extracted microcystins. Bull Environ Contam Toxicol 82, 574-578.

15. Pi J, Zhang Q, Fu JG, et al. (2010) ROS signaling, oxidative stress and Nrf2 in pancreatic beta-cell function. Toxicol Appl Pharmacol 244, 77-83.

16. Jin Y, Zheng S, Pu Y, et al. (2010) Cypermethrin has the potential to induce hepatic oxidative stress, DNA damage 
and apoptosis in adult zebrafish (Danio rerio). Chemosphere 82, 398-404.

17. Carnevalli O, de Vivo L, Sulpicio R, et al. (2006) Growth improvement by probiotic in European sea bass (Dicentrarchus labrax, L.) juveniles, with particular attention to IGF-1, myostatin and cortisol gene expression. Aquaculture 258, 430-438.

18. Watkins BA \& Seifert MF (2000) Conjugated linoleic acid and bone biology. J Am Coll Nutr 19, 478-486.

19. Lall SP \& Lewis-McCrea LM (2007) Role of nutrients in skeletal metabolism and pathology in fish - an overview. Aquaculture 267, 3-19.

20. Hall BK \& Witten PE (2007) Plasticity of and transitions between skeletal tissues in vertebrate evolution and development. In Major Transitions in Vertebrate Evolution, pp. 56-69 [JS Anderson and DH Sues, editors]. Bloomington, IN: Indiana University Press.

21. Huxley $\mathrm{TH}$ (1859) Observations on the development of some parts of the skeleton of fishes. Quar J Microscop Sci 7, 33-46.

22. Arratia G, Schultze HP \& Casciotta J (2001) Vertebral column and associated elements in dipnoans and comparison with other fishes: development and homology. J Morphol 250, 101-172.

23. Fernández-Palacios H, Izquierdo MS, Robaina L, et al. (1995) Effect of $n$-3 HUFA level in broodstock diets on egg quality of gilthead seabream (Sparus aurata L.). Aquaculture 132, 325-337.

24. Izquierdo MS, Watanabe T, Takeuchi T, et al. (1989) Optimal EFA levels in Artemia to meet the EFA requirements of red seabream Pagrus major. In The Current Status of Fish Nutrition in Aquaculture, pp. 221-232 [M Takeda and T Watanabe, editors]. Tokyo: Japan Translation Centre.

25. Vandewalle P, Gluckmann I \& Wagemans F (1998) A critical assessment of the alcian blue/alizarin double staining in fish larvae and fry. Belgian J Zool 128, 93-95.

26. Boglione C, Gagliardi F, Scardi M, et al. (2001) Skeletal descriptors and quality assessment in larvae and postlarvae of wild caught and hatchery reared gilthead sea bream (Sparus aurata L. 1758). Aquaculture 192, 1-22.

27. Folch J, Lees M \& Sloane Stanley GH (1957) A simple method for the isolation and purification of total lipides from animal tissues. J Biol Chem 226, 497-509.

28. Christie WW (1989) Gas Chromatography and Lipids: A Practical Guide. Glasgow: The Oily Press.

29. Izquierdo MS, Arakawa T, Takeuchi T, et al. (1992) Effect of $n$-3 HUFA levels in Artemia on growth of larval Japanese flounder (Paralichthys olivaceus). Aquaculture 105, 73-82.

30. AOAC (1995) Official Methods of Analysis of the Association Analytical Chemistries. Arlington, VA: AOAC.

31. Burk RF, Trumble MJ \& Lawrence RA (1980) Rat hepatic cytosolic GSH-dependent enzyme protection against lipid peroxidation in the NADPH microsomal lipid peroxidation system. Biochim Biophys Acta 618, 35-41.

32. Tocher DR, Mourente G, van der Eecken A, et al. (2002) Effects of dietary vitamin $\mathrm{E}$ on antioxidant defence mechanisms of juvenile turbot (Scophtalmus maximus), halibut (Hippoglossus hippoglossus L.) and sea bream (Sparus aurata). Aquaculture Nutr 8, 195-207.

33. Izquierdo MS \& Koven W (2010) Lipids. In Larval Fish Nutrition, pp. 47-82 [J Holt, editor]. New York: Wiley-Blackwell.

34. Izquierdo MS (2005) Essential fatty acids requirements in Mediterranean fish species. Cah Opt Med 63, 91-101.

35. Liu J, Caballero MJ, Izquierdo MS, et al. (2002) Necessity of dietary lecithin and eicosapentaenoic acid for growth, survival, stress resistance and lipoprotein formation in gilthead seabream Sparus aurata. Fish Sci 225, 325-340.

36. Rodríguez C, Pérez JA, Badía P, et al. (1998) The $n$-3 highly unsaturated fatty acids requirements of gilthead sea bream (Sparus aurata L.) larvae when using an appropriate DHA/ EPA ratio in the diet. Aquaculture 169, 9-23.

37. Kranenbarg S, Waarsing JH, Muller M, et al. (2005) Lordotic vertebrae in sea bass (Dicentrarchus labrax L.) are adapted to increased loads. J. Biomech 38, 12-39.

38. Kruger MC, Coetzee M, Haag M, et al. (2010) Long-chain polyunsaturated fatty acids: selected mechanisms of action on bone. Prog Lipid Res 49, 438-449.

39. Kruger MC \& Schollum LM (2005) Is docosahexaenoic acid more effective than eicosapentaenoic acid for increasing calcium bioavailability? Prostaglandins Leukot Essen Fatty Acids 73, 327-334.

40. Raisz LG, Alander CB \& Simmons HA (1989) Effects of prostaglandin $\mathrm{E}_{3}$ and eicosapentaenoic acid on rat bone in organ culture. Prostaglandins 37, 615-625.

41. Serhan CN (2005) Novel eicosanoid and docosanoid mediators: resolvins, docosatrienes and neuroprotectins. Curr Opin Clin Nutr Metab Care 8, 115-121.

42. Ganga R, Tort L, Acerete L, et al. (2006) Modulation of ACTH-induced cortisol release by polyunsaturated fatty acids in interregnal cells from gilthead seabream, Sparus aurata. J Endocrinol 190, 39-45.

43. Ganga R, Bell GJ, Montero D, et al. (2011) Adrenocorticotrophic hormone-stimulated cortisol release by the head kidney interrenal tissue from sea bream (Sparus aurata) fed with linseed oil and soyabean oil. Br J Nutr 105, $238-247$.

44. Fernandes G, Bhattacharaya A, Rahman M, et al. (2008) Effects of $n$ - 3 fatty acids on autoimmunity and osteoporosis. Front Biosci 13, 4015-4020.

45. Pozios KC, Ding J, Degger B, et al. (2001) IGFs stimulate zebrafish cell proliferation by activating MAP kinase ans PI3-kinase-signalling pathways. $A m J$ Physiol 280, 1230-1239.

46. Collins DA \& Chambers TJ (1991) Effect of prostaglandins $E_{1}$, $\mathrm{E}_{2}$, and $\mathrm{F}_{2 \mathrm{a}}$ on osteoclast formation in mouse bone marrow cultures. J Bone Miner Res 6, 157-164.

47. Pombinho AR, Laize V, Molha DM, et al. (2004) Development of two bone-derived cell lines from the marine teleost Sparus aurata: evidence for extracellular matrix mineralization and cell-type-specific expression of matrix Gla protein and osteocalcin. Cell Tissue Res 315, 393-406.

48. Komondouros G (2010) Morpho-anatomical abnormalities in Mediterranean marine aquaculture. Recent Adv Aquacult Res 2010, 125-148.

49. Betancor MB, Atalah E, Caballero MJ, et al. (2010) Alphatocopherol in weaning diets for European sea bass (Dicentrarchus labrax) improves survival and reduces tissue damage caused by excess dietary DHA contents. Aquaculture Nutr 17, 112-122.

50. Beer AM \& Wegener T (2011) Vitamin E for gonarthrosis and coxarthrosis: results of a postmarketing surveillance study. Fortschr Med 153, 14-20.

51. Dabrowski K, El-Fiky N, Köck G, et al. (1990) Requirement and utilization of ascorbic acid and ascorbic sulfate in juvenile rainbow trout. Aquaculture 91, 317-337.

52. Atalah E (2008) Importance of the proportions of polyunsaturated fatty acids and antioxidants in larval development of marine fish. PhD Thesis, Universidad de Las Palmas de Gran Canaria, Spain. 